\title{
Mechanical Properties of Reinforced Denture Base Resin: The Effect of Position and the Number of Woven Glass Fibers
}

\author{
Takahito KANIE, Hiroyuki ARIKAWA, Koichi FUJII \\ and Seiji BAN \\ Department of Biomaterials Science, Kagoshima University Dental School \\ 8-35-1 Sakuragaoka, Kagoshima 890-8544, Japan
}

Received April 15, 2002/Accepted June 24, 2002

\begin{abstract}
This study examined the effects of the position and the number of woven glass fibers on the flexural strength, flexural modulus, and toughness of reinforced denture base resin. The woven glass fiber consisted of 1-4 laminated sheets. Chemical curing was used to polymerize three types of 4-mm-thick test specimens: fibers in compression, fibers in the center, and fibers in tension. Unreinforced specimens were produced as controls. A three-point flexural test was performed and the woven glass fiber content was calculated after the woven glass fiber was fired. The best results were obtained when the woven glass fiber was incorporated outside the base resin under tension, thereby increasing the flexural strength and flexural modulus. Furthermore, the denture base resin reinforced with woven glass fiber was made tougher by increasing the number of woven glass fibers incorporated into the portion under tension.
\end{abstract}

Key words: Denture base resin, Woven glass fiber, Mechanical property

\section{INTRODUCTION}

At present, though acrylic denture base resin is widely used, acrylic denture base resin is also desired to fulfill the mechanical requirements of prosthesis and to be thin similar to the cast denture base. For strengthening, one method used to reinforce the acrylic denture base resin is PMMA-fibers such as metal, glass, carbon, Aramid and PE, which have been investigated ${ }^{1)}$. In 1999, Jagger ${ }^{2)}$ classified and discussed each feature of strengtheners of denture base in detail.

The traditional method involves using either metal wires or plates as strengtheners in the denture base. However, mechanical retention between embedded metal wire and PMMA leads to cracks in the denture base by causing stress concentration $^{3,4)}$. Furthermore, there are some demerits that the repair is difficult in cases with cracks in the denture base, where the embedding is not easy because of stiffness and the color of the resin blackens. Although the mechanical retention with PMMA is improved in applications of 4META, the acrylic denture base resin is used, while the above problem remains ${ }^{5}$.

Glass fiber, which has good adhesion with PMMA, has been studied in many forms for strengtheners including woven, loose and continuous such as roving or fiber bundles. Stipho ${ }^{6)}$ suggested that $1 \%$ glass fiber in denture base resins enhanced their transverse strength, and Vallittu ${ }^{7)}$ reported that increased amounts of fibers in 
PMMA matrix (up to $14.8 \mathrm{wt} \%$ ) increased the tensile strength and E-modulus. Furthermore, our previous study ${ }^{8)}$ showed that in thick specimens the reinforcing effect increases with the number of glass fibers. Therefore, the glass fiber content is an important consideration in denture base resins using fiber reinforcement ${ }^{9)}$.

Flexural stress is one of forces related to the breakage of denture bases, because chewing introduces complex stresses on dental appliances ${ }^{10-12}$. This stress produces tensile or compressive stresses in the acrylic denture base resin. As Jagger ${ }^{2)}$ mentioned, the position of the incorporated glass fiber in dental applications is a complex problem, since each product is handmade and the fibers are incorporated into the resin by hand.

It appears to be necessary to uniformly reinforce the resin plate in order to thin the denture base. For this purpose, the long fiber must uniformly disperse in the denture base or must be used in cloth form. However, few studies ${ }^{13-15)}$ have examined the effect of the cloth form of glass fiber.

This study measured the flexural strength, flexural modulus and toughness of reinforced resin. In this manner, the effect of the number and position of woven glass fiber on the mechanical properties was examined.

\section{MATERIALS AND METHODS}

\section{Manufacture of test specimens}

The properties gives by the manufacturer of the woven glass fiber (Mie Fabrics, Mie, Japan) used are shown in the Table. The woven glass fiber was cleaned by boiling in water for $1 \mathrm{hr}$, and then dried in air. $\gamma$-Methacryloxypropyltrimethoxysilane ( $\gamma$-MPTS) (Toray Dow Corning Silicone Ltd., Tokyo, Japan) was used as a silanecoupling agent. The woven glass fiber was cut into $100 \times 50-\mathrm{mm}$ sheets with shears

Table Some properties of the woven glass fiber

\begin{tabular}{ccccc}
\hline \multirow{2}{*}{ Trade name } & Texture & $\begin{array}{c}\text { Standard thickness } \\
(\mathrm{mm})\end{array}$ & $\begin{array}{c}\text { Tensile strength } \\
(\mathrm{N} / 25 \mathrm{~mm})\end{array}$ & $\begin{array}{c}\text { Density } \\
\text { (threads } / 25 \mathrm{~mm})\end{array}$ \\
\hline YEA1801 & Satin elastic webbing & 0.16 & 1451 & 46 \\
\hline
\end{tabular}

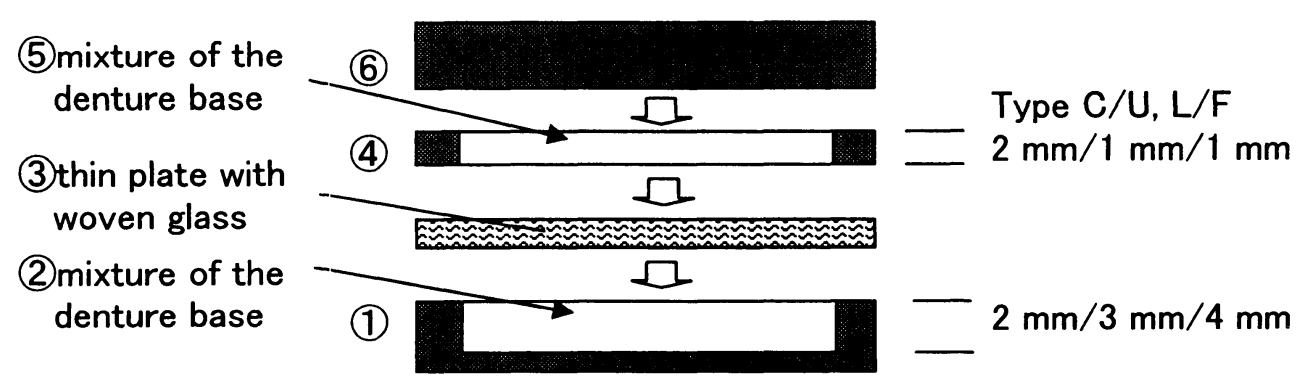

Fig. 1 Method of making of the thin plate containing woven glass fiber. 


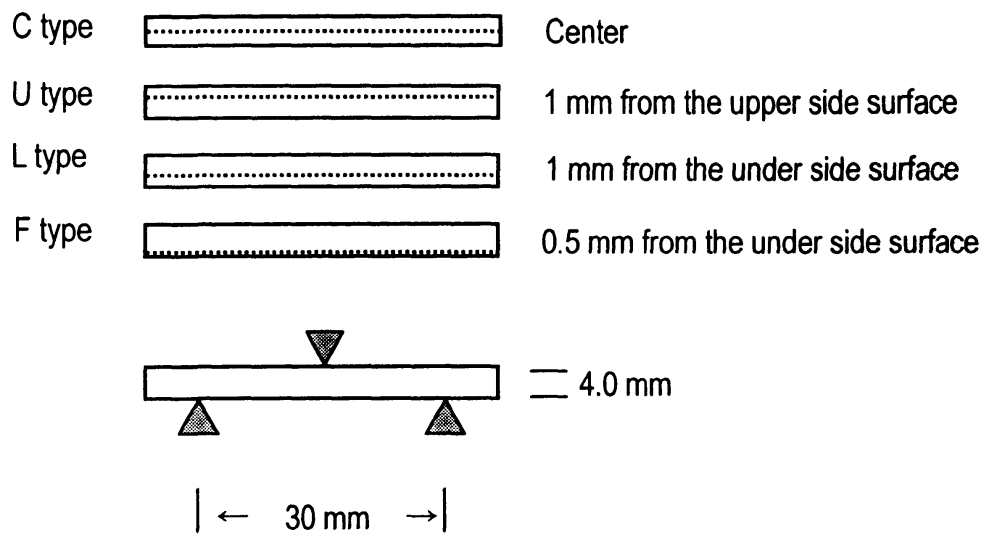

Fig. 2 Code, positions of the woven glass fiber and loading method.

and soaked in $2 \%-\gamma$-MPTS-ethanol solution for $10 \mathrm{~min}$. The woven glass fiber was then removed, dried in air for $3 \mathrm{hr}$, and heated at $115^{\circ} \mathrm{C}$ for $10 \mathrm{~min}$. After sandwiching $1,2,3$, or 4 sheets of the silanized woven glass fiber between two Teflon boards, they were sealed with aluminum foil. BPO was added to a liquid (MMA) of denture base resin (Pour Resin, Shofu Inc., Kyoto, Japan) at $1 \mathrm{wt} \%$ and injected into the space containing the woven glass fiber and allowed to polymerize into a thin plate by heating at $50^{\circ} \mathrm{C}$ for $30 \mathrm{~min}$. The average thickness of the thin plate containing 1,2 , 3 , or 4 sheets of the woven glass fiber was $0.55,0.78,1.06$ and $1.28 \mathrm{~mm}$. Then, a thin plate was put in another Teflon mold with a concavity and a mixture in a powder (PMMA) of denture base resin (Pour Resin, Shofu Inc., Kyoto, Japan): liquid ratio of $9 \mathrm{~g}: 5 \mathrm{ml}$ was poured into the Teflon mold (Fig.1). This was polymerized by heating at $50^{\circ} \mathrm{C}$ for $30 \mathrm{~min}$. The polymerized composite sheet was about $4 \mathrm{~mm}$ thick. After polymerization, the composite block was cut with a water-cooled diamond blade, and polished to $8 \times 4 \times 40 \mathrm{~mm}$ using Emery paper. The thickness $(4 \mathrm{~mm})$ of test specimens was decided to clarify the difference in the positions between $\mathrm{L}$ type and $\mathrm{F}$ type. Fig. 2 shows the positions of the incorporated woven glass fiber and the method of loading the test specimens. F type was made using a composite sheet with 2 woven glass fibers.

\section{Three-point flexural test}

A universal test machine (TG-2300, Minebea Co. Ltd., Tokyo, Japan) was used to measure the mechanical properties using the three-point flexural test. The crosshead speed was $2 \mathrm{~mm} / \mathrm{min}$ and the span length was $30 \mathrm{~mm}$. The flexural strength $\left(\mathrm{F}_{\mathrm{S}}\right)$ and flexural modulus $\left(\mathrm{F}_{\mathrm{E}}\right)$ were calculated using the formulae :

$$
\begin{aligned}
& \mathrm{F}_{\mathrm{S}}=\frac{3 P_{m} l}{2 b h^{2}} \\
& \mathrm{~F}_{\mathrm{E}}=\frac{l^{3} P_{x}}{4 b h^{3} d}
\end{aligned}
$$


where $P_{m}$ is the maximum load, $l$ is the span length, $b$ is the width of the test specimen, $h$ is the thickness of the test specimen, and $d$ is the deflection corresponding to load linear position. The toughness was calculated from the energy from the start of stress to the largest stress using stress-strain curves.

\section{Woven glass fiber content}

Test specimens of the same dimensions as those used in the flexural test were dried in an oven at $37^{\circ} \mathrm{C}$ for $24 \mathrm{hr}$, and weighed $\left(W_{a}\right)$ with an analytical balance. Then, the polymer was dissolved by soaking the test specimen in THF. The remaining woven glass fiber was removed from the THF, dried, and then fired in a porcelain crucible at $600^{\circ} \mathrm{C}$ for $1 \mathrm{hr}$. The woven glass fiber was reweighed $\left(W_{g}\right)$ after it had cooled. The content rate $\left(W_{g} / W_{a}\right)$ was calculated and averaged for three samples.

\section{Statistical analysis}

Six test specimens were used for each flexural test. Unreinforced specimens (US) that contained no woven glass fiber were made by the same method to act as controls. A one-way analysis of variance (ANOVA) and Tukey's test were used to compare the difference in the mechanical strength according to a three-point flexural test. A two-way ANOVA was conducted incorporating the position of the woven glass fiber and the woven glass fiber content as independent variables and the mechanical properties as the dependent variable.

\section{RESULTS}

The flexural strengths of the specimens are shown in Fig. 3. The flexural strengths

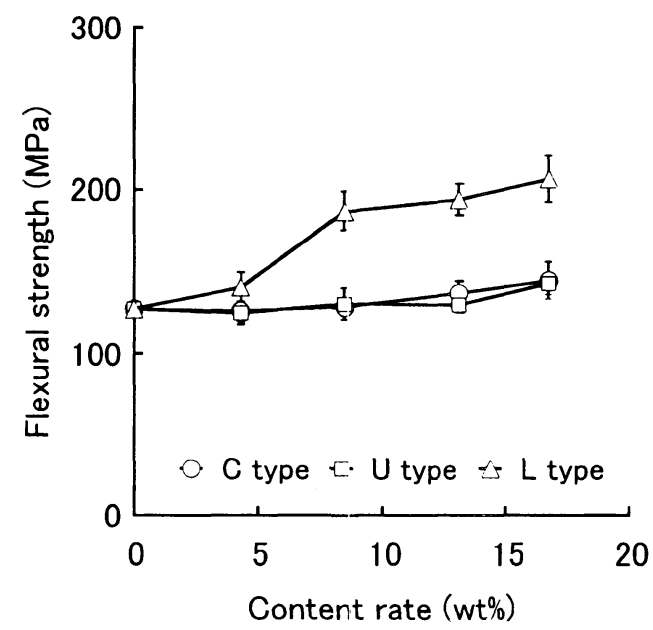

Fig. 3 Flexural strength of reinforced test specimens plotted against the content rate of woven glass fiber.

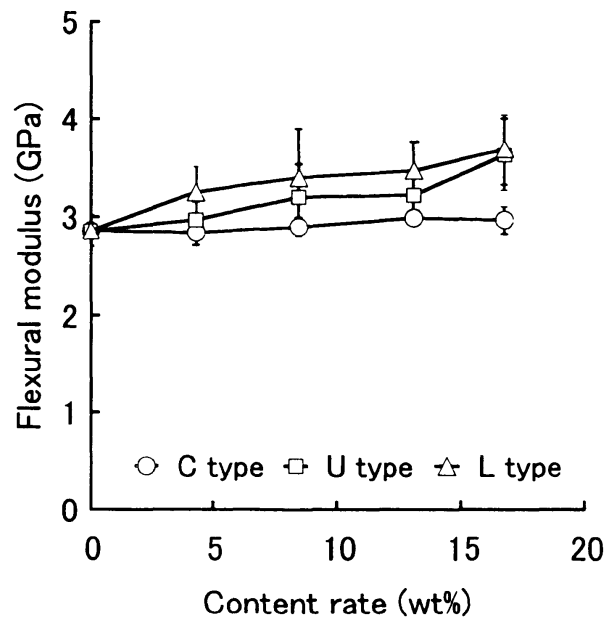

Fig. 4 Flexural modulus of reinforced test specimens plotted against the content rate of woven glass fiber. 


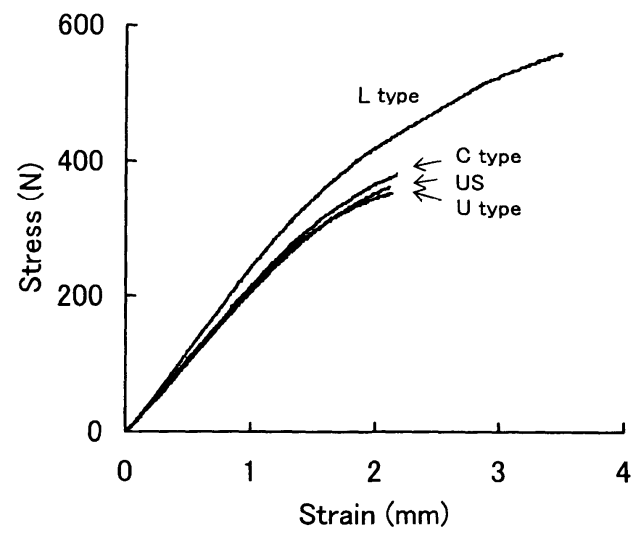

Fig. 5 Stress-strain curves of US, and C, $\mathrm{U}$ and $\mathrm{L}$ types with 4 composite sheets.

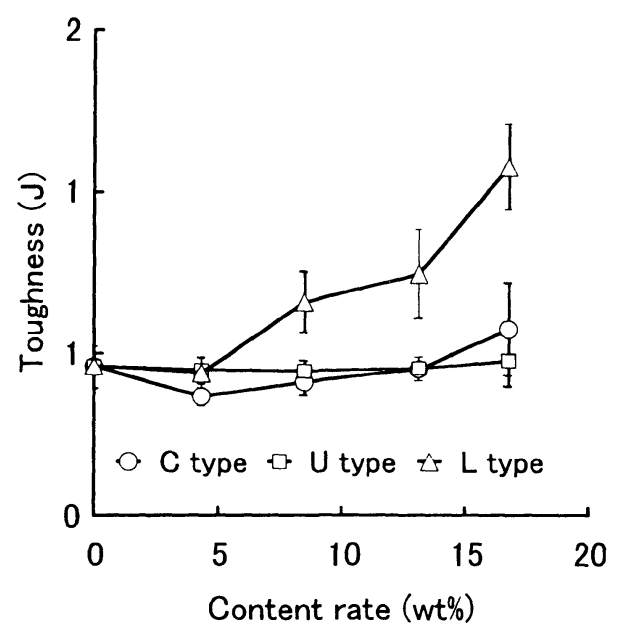

Fig. 6 Toughness of reinforced test specimens plotted against the content rate of woven glass fiber.

of $\mathrm{C}$ and $\mathrm{U}$ types with 4 composite sheets were 144.7 and $143.0 \mathrm{MPa}$, respectively, and were significantly different from that of US $(127.2 \mathrm{MPa})(p<0.05)$. The flexural strengths of L type with 2, 3, and 4 composite sheets were 186.8, 194.1, and 206.6 $\mathrm{MPa}$, respectively, and increased with the number of woven glass fiber sheets. There was an interaction between the position and the contents of the woven glass fiber content by two-way ANOVA at the $5 \%$ level $(p<0.05)$.

The flexural moduli are shown in Fig. 4. The flexural moduli of $U$ type with 4 composite sheets and L type with 3 and 4 composite sheets were 3.63, 3.47, and 3.69 $\mathrm{GPa}$, respectively, and were significantly different from the flexural modulus of US $(2.86 \mathrm{GPa})(p<0.05)$. However, there was no interaction between the position and woven glass fiber content by two-way ANOVA $(p>0.05)$.

The toughness of the specimens, which corresponds to the energy from the start of the stress to the largest flexural stress in the stress-strain curves, is shown in Figs. 5 and 6 . The toughness of $\mathrm{L}$ type with 2, 3, and 4 composite sheets was 0.661 , 0.747 , and $1.078 \mathrm{~J}$, respectively, and was superior to that of US $(0.458 \mathrm{~J})(p<0.05)$. The two-way ANOVA showed an interaction between the position and woven glass fiber content $(p<0.05)$.

The flexural strength and flexural modulus of $\mathrm{L}$ type and $\mathrm{F}$ type with 2 composite sheets, for which the distance of the incorporated woven glass fiber from the subsurface varied, are shown in Figs. 7 and 8. The flexural strength and flexural modulus of the $\mathrm{F}$ type $(227.5 \mathrm{MPa}$ and $4.94 \mathrm{GPa})$ and L type were significantly different $(p<0.05)$.

The toughness of the $\mathrm{L}$ type and $\mathrm{F}$ type with 2 composite sheets $(0.717 \mathrm{~J})$ is shown in Fig. 9. The differences between $\mathrm{F}$ type with 2 composite sheets and $\mathrm{L}$ type with 2 composite sheets, and between $\mathrm{F}$ type with 2 composite sheets and L type with 


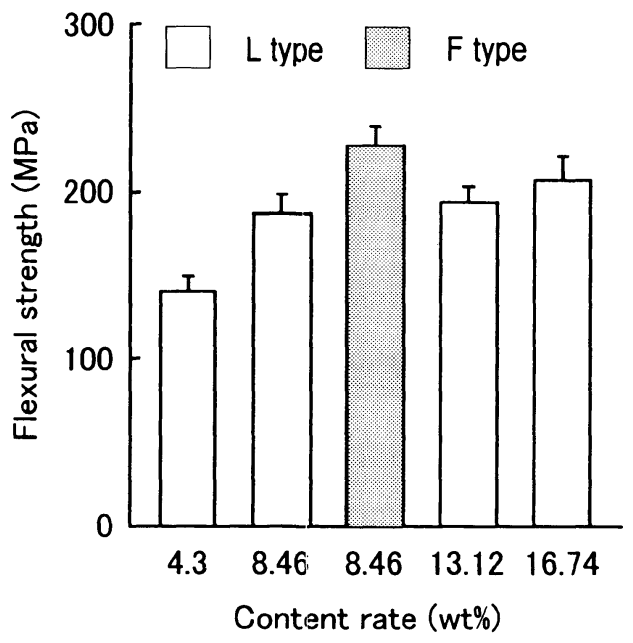

Fig. 7 Flexural strength of $\mathrm{L}$ type and $\mathrm{F}$ type with 2 composite sheets.

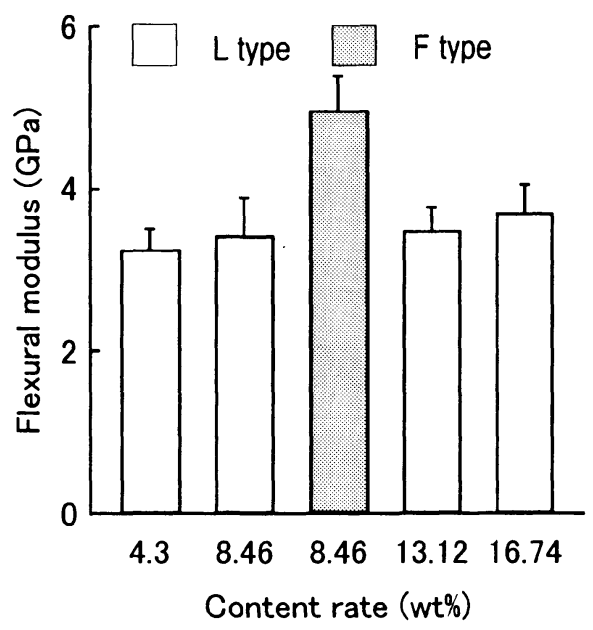

Fig. 8 Flexural modulus of $\mathrm{L}$ type and F type with 2 composite sheets.

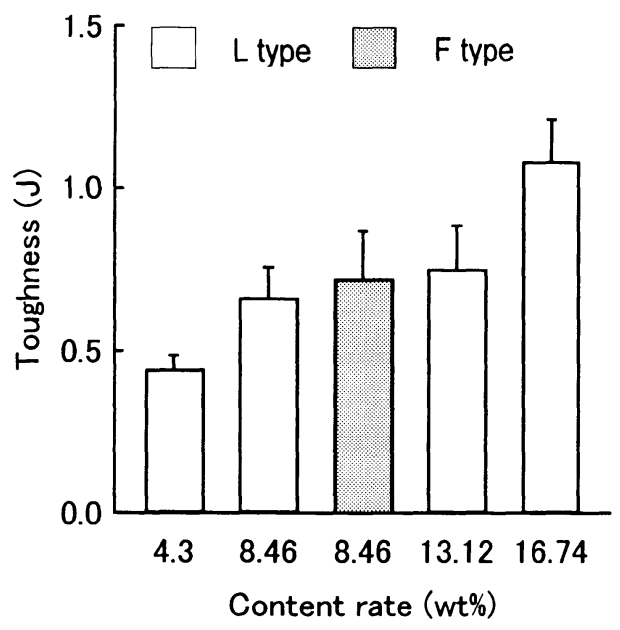

Fig. 9 Toughness of $\mathrm{L}$ type and $\mathrm{F}$ type with 2 composite sheets.

3 composite sheets were not significant $(p>0.05)$.

\section{DISCUSSION}

In general, the glass is lighter than the metal and chemically bonds to the PMMA by the silanization easily. Glass fiber is more excellent in esthetics than the metal and can be used with light-curing denture base resin because of the good optical transparency. Furthermore, the repair of the denture base is easier than in cases where 
metal wire was used, when the cracks in the denture base were unfortunately caused during use.

The woven glass fiber used in this investigation can be cut-off as well as the cloth using scissors in the free form and the molding is also easy. In future usage, as Vallittu ${ }^{12)}$ reported, the technical procedure can be simplified by prepregnating the woven glass fiber.

Jennings et $a l^{16)}$ and Ruffino ${ }^{17)}$ and Mullarky ${ }^{18)}$ discussed the effects of reinforcement on the mechanical properties of denture base resin. These studies clearly showed that the reinforcement is stronger than the matrix resin when some kind of reinforcing materials (such as metal or Aramid) is used. Considering the shape of the denture base resin appliance, it is necessary not only to be strong but also flexibility. Therefore, we studied the effects of using laminated layers of flexible woven glass fiber in the matrix resin.

While the flexural strength of $U$ type with 4 composite sheets, which was about $17 \mathrm{wt} \%$ woven glass fiber, was $12 \%$ greater than that of US, the reinforcing effect in the position of the woven glass fibers during compression was small. On the other hand, the flexural strength of the $L$ type increased markedly with the amount of the woven glass fiber. In addition, there was an interaction between the position and content of the woven glass fiber (Fig. 3). However, no correlation between flexural strength and the number of woven glass fibers was observed in the L type samples $(\mathrm{y}=4.902 \mathrm{x}+129.754, \mathrm{r}=0.922, p=0.0785)$. The woven glass fiber sheets on the subsurface side of the matrix produce a depression effect against drawing of the matrix resin. If the tensile strength of the reinforcing material is sufficiently stronger than that of the matrix resin, increasing the number of reinforcing sheets may have a small effect.

In this study, the flexural strength of the $L$ type samples was enhanced when the woven glass fiber content exceeded $8 \mathrm{wt} \%$ (Fig. 3). The flexural strength of L type with 2,3 and 4 composite sheets increased by 47,53 , and $62 \%$ compared with US, respectively. Shimozato et $a{ }^{19}{ }^{19)}$ found that the flexural strength of denture base resin reinforced with carbon fiber increased by $35 \%$ and Inanaga et al. ${ }^{20)}$ found that the flexural strength of the denture base polymer reinforced with carbon and aramid fibers increased by $6 \%$. Furthermore, our previous investigation ${ }^{8)}$ showed that the flexural strength of 1 -mm-thick test specimens reinforced with woven glass fiber increased by 16 to $25 \%$. These differences may result in the complex interactions due to differences in the strength, shape, and thickness of the reinforcing material and the adhesive property of the matrix resin.

The flexural strength of $\mathrm{C}$ type with 4 composite sheets was significantly higher than US (Fig. 3). A previous study ${ }^{8)}$ suggested that woven glass fiber prevents the spread of the resin matrix during the flexural test. It is likely that the thick layer of woven glass fiber at the center of the test specimens filled this role.

The flexural strength of $\mathrm{F}$ type was significantly higher than that of $\mathrm{L}$ type (Fig. 7). This result agreed with that of a previous study ${ }^{21)}$, which used metal strengthener, and suggests that the position of the woven glass fiber is important. 
When a load was applied in the flexural test, tension occurred below the neutral axis of the specimen. The woven glass fiber suppressed drawing of the material under tension. Therefore, it is important to place the woven glass fiber in an outside position in the matrix resin, where tension acts on the specimen.

The fluctuation in the flexural modulus was smaller than that in flexural strength or toughness, and no interaction between the position and content of the woven glass fiber was recognized in the ANOVA analysis. In the early stages of the flexural test, i.e., for stresses under linear proportion limits, the subsurface of the test specimen lengthened slightly. Therefore, the flexural modulus measured at this point was not influenced by the strength of the woven glass fiber. However, when the woven glass fiber was moved towards the outer side of the resin matrix ( $F$ type), the flexural modulus was significantly higher (Fig. 8). When in this position, at a stress of linear proportion, the woven glass fiber clearly controlled the drawing of the resin matrix.

The toughness of $\mathrm{L}$ type increased with the increase in the number of woven glass fibers. Moreover, the increase in toughness with woven glass fiber content was larger than the increase in flexural strength. This implies that woven glass fiber reinforcement delays the time it takes for the reinforced resin to lengthen and then break. There was an interaction between the position and content of the woven glass fiber in the two-way ANOVA for toughness. However, no significant effect on toughness was observed, even when the woven glass fiber was positioned towards the outer side of the matrix (Fig.9). When the woven glass fiber was placed in the inner portion of the matrix, which increased tensile strength, it appeared to suppress drawing of the matrix resin and to delay breaking. This suggests that for toughness, the number of woven glass fibers is of more importance than their position.

Polymethylmethacrylate is commonly used as a denture base resin, but it is necessary to make a denture base resin that is more difficult to break. The present results suggest that the addition of brittle woven glass fiber reinforcement serves this purpose. To increase the flexural strength and flexural modulus, woven glass fiber, which excels in tensile strength, was incorporated outside the area of tension as much as possible. Furthermore, the flexural strength and toughness of denture base resin reinforced with woven glass fiber was enhanced by increasing the number of woven glass fibers incorporated into the matrix resin under tension.

\section{REFERENCES}

1) Vallittu, P.K.: Comparison of the in vitro fatigue resistance of an acrylic resin removable partial denture reinforced with continuous glass fibers or metal wires, $J$ Prosthodont 5 : 115-121, 1996.

2) Jagger, D. C.: The reinforcement of dentures, J Oral Rehabil 26(3) : 185-194, 1999.

3) Toyoda, M., Sugimura, D., Aoki, T., Saito, M., Hama, A. and Matsuo, E.: Study on relationship between reinforcing wires and metal bonding type denture base resin, Kanagawashigaku 30(3) : 286-292, 1995. (in Japanese)

4) Sugimura, D.: A study on effect of reinforcing materials for denture base resin, Kanagawashigaku 31(2): 164-179, 1996. (in Japanese) 
5) Kato, K., Sakuma, T. and Nagayama, K.: Reinforcement of denture base resin with metal wire, Ohudaishigakushi 27(2):82-86, 2000. (in Japanese)

6) Stipho, H. D.: Effect of glass fiber reinforcement on some mechanical properties of autopolymerizing polymethyl methacrylate, J Prosthet Dent 79(5) : 580-584, 1998.

7) Vallittu, P. K.: Some aspects of the tensile strength of unidirectional glass fibrepolymethyl methacrylate composite used in dentures, J Oral Rehabil 25(2): 100-105, 1998.

8) Kanie, T., Fujii, K., Arikawa, H. and Inoue, K.: Flexural properties and impact strength of denture base polymer reinforced with woven glass fibers, Dent Mater 16 : 150$158,2000$.

9) Vallittu, P. K., Lassila, V. P. and Lappalainen, R.: Acrylic resin-fiber composite -part I The effect of fiber concentration on fracture resistance, $J$ Prosthet Dent 71(6):607-612, 1994.

10) Vallittu, P. K., Lassila, V. P. and Lappalainen, R.: Transverse strength and fatigue of denture acrylic-glass fiber composite, Dent Mater 10 :116-121, 1994.

11) Vallittu, P. K., Vojtkova, H. and Lassila, V. P.: Impact strength of denture polymethyl methacrylate reinforced with continuous glass fibers or metal wire, Acta Odontol Scand $53: 392-396,1995$.

12) Vallittu, P. K.: Flexural properties of acrylic resin polymers reinforced with unidirectional and woven glass fibers, $J$ Prosthet Dent 81(3) : 318-326, 1999.

13) Uzun, G., Hersek, N. and Tinser, T.: Effect of five woven fiber reinforcements on the impact and transverse strength of a denture base resin, $J$ Prosthet Dent 81(5) : 616-620, 1999.

14) Solnit, G. S.: The effect of methyl methacrylate reinforcement with silane-treated and untreated glass fibers, $J$ Prosthet Dent 66(3) : 310-314, 1991.

15) Vallittu, P. K., Ruyter, I. E. and Ekstrand, K.: Effect of water storage on the flexural properties of E-glass and silica fiber acrylic resin composite, Int $J$ Prosthodont 11(4) : 340-350, 1998.

16) Jennings, R.E. and Wuebbbenhorst, A. M.: The effect of metal reinforcements on the transverse strength of acrylic resin, J Dent Child 27: 162-168, 1960.

17) Ruffino, A. R.: Effect of steel strengtheners on fracture resistance of the acrylic resin complete denture base, $J$ Prosthet Dent 54(1): 75-78, 1985.

18) Mullarky, R. H.: Aramid fiber reinforcement of acrylic appliances, $J$ Clinic Orthodont 19 (9) : 655-658, 1985.

19) Shimozato, T., Yamanaka, A., Kurata, S. and Yamazaki, N.: Denture base PMMA resins reinforced with carbon fibers Part 1 Surface treatments of the carbon fiber $s$ and its effects on flexural and tensile strength of the reinforced resins, The $J$ Jpn Soc Dent Mater and Device 3(5): 648-654, 1984. (in Japanese)

20) Inanaga, A., Naka, S., Takahashi, Y., Tchii, D., Yoshinaga, M., Habu, T. and Miyazaki, K.: Studies on denture base resins reinforced with carbon or aramid fiber Part 1. The effectiveness of including fiber and surface treatments, $J$ Jpn Prosthodont Soc 37(5): 1083-1090, 1993. (in Japanese)

21) Kimura, F.: Fundamental study on metal strengthener for acrylic resin denture, $J \mathrm{Kyu}$ shu Dent Soc, 34(6) : 665-677, 1981. (in Japanese) 